\title{
Prevention of calcification of glutaraldehyde-crosslinked porcine aortic cusps by ethanol preincubation: Mechanistic studies of protein structure and water-biomaterial relationships
}

\author{
Narendra R. Vyavahare, ${ }^{1}$ Danielle Hirsch, ${ }^{1}$ Eyal Lerner, ${ }^{1}$ Jonathan Z. Baskin, ${ }^{1}$ Robert Zand, ${ }^{2}$ \\ Frederick J. Schoen, ${ }^{3}$ Robert J. Levy ${ }^{1}$ \\ ${ }^{1}$ Department of Pediatrics and Communicable Diseases, University of Michigan, Ann Arbor, Michigan \\ ${ }^{2}$ Department of Biological Chemistry and Macromolecular Science and Engineering and the Biophysics Research \\ Division, University of Michigan, Ann Arbor, Michigan \\ ${ }^{3}$ Department of Pathology, Brigham and Women's Hospital and Harvard Medical School, Boston, Massachusetts
}

Received 4 April 1997; accepted 22 August 1997

\begin{abstract}
Clinical usage of bioprosthetic heart valves (BPHVs) fabricated from glutaraldehyde-pretreated porcine aortic valves is restricted due to calcification-related failure. We previously reported a highly efficacious ethanol pretreatment of BPHVs for the prevention of cuspal calcification. The aim of the present study is to extend our understanding of the material changes brought about by ethanol and the relationship of these material effects to the ethanol pretreatment anticalcification mechanism. Glutaraldehydecrosslinked porcine aortic valve cusps (control and ethanolpretreated) were studied for the effects of ethanol on tissue water content and for spin-lattice relaxation times (T1) using solid state proton NMR. Cusp samples were studied for protein conformational changes due to ethanol by ATR-FTIR spectroscopy. The changes in cuspal tissue-cholesterol (in vitro) interactions also were studied. Cusp material stability was assessed in terms of residual glutaraldehyde content and collagenase degradation. Water content of the cusp
\end{abstract}

samples was decreased significantly due to ethanol pretreatment. The cuspal collagen conformational changes (per infrared spectroscopy) brought about by ethanol pretreatment were persistent even after rat subdermal implantation of cusp samples for 7 days. In vitro cholesterol uptake by cusps was greatly reduced as a result of ethanol pretreatment. Ethanol pretreatment of cusps also resulted in increased resistance to collagenase digestion. Cuspal glutaraldehyde content was not changed by ethanol pretreatment. We conclude that ethanol pretreatment of bioprosthetic heart valve cusps causes multi-component effects on the tissue/material and macromolecular characteristics, which partly may explain the ethanol-pretreatment anticalcification mechanism. (C) 1998 John Wiley \& Sons, Inc. J Biomed Mater Res, 40, 577-585, 1998.

Key words: bioprostheses; type I collagen; infrared spectroscopy

\section{INTRODUCTION}

Calcification is one of the major causes of the failure of bioprosthetic heart valves derived from glutaraldehyde-pretreated bovine pericardium or porcine aortic valves. $^{1-3}$ The mechanism of this type of pathologic calcification is incompletely understood. In animal

Correspondence to: R. J. Levy, Pediatric Cardiology Division, Abramson Pediatric Research Center, Suite 1107, Children's Hospital of Philadelphia, 34th Street and Civic Center Blvd., Philadelphia, PA 19104; e-mail: levyr@email.chop.edu

Contract grant sponsor: National Institutes of Health; Contract grant number: HL38118

Contract grant sponsor: St. Jude Medical, Inc.

(c) 1998 John Wiley \& Sons, Inc.

CCC 0021-9304/98/040577-09 models, it has been shown that initial nucleation sites are cell membranes, the nucleus, and intracellular organelles, such as the mitochondria of devitalized cells. With increasing duration of implantation, cellassociated calcific deposits increase in size and number. Direct collagen calcification in cusps and elastin calcification in the aortic wall subsequently occur. Various host factors, such as the young age of a recipient, and implant factors, such as glutaraldehyde fixation, also aggravate calcification events. Although various strategies are under investigation for preventing this disease process, no clinically proven method is yet available.

In a recent publication, ${ }^{4}$ we reported that ethanol preincubation of glutaraldehyde-crosslinked porcine aortic valve bioprostheses is a highly efficacious pretreatment for preventing calcification of porcine aortic 
valve cusps in both 60-day rat subdermal implants and sheep mitral valve replacements (150 days). Ethanol was chosen as an anticalcification agent due to its known interference in the cellular metabolism of calcium in bone-line cells as well as in fibroblasts. ${ }^{5,6}$ The presence of ethanol has been shown to break down cellular membranes and disorder acyl chains of phospholipids that affect many cellular activities. ${ }^{7}$ Furthermore, ethanol has been shown to significantly inhibit calcium phosphate nucleation and phase transformations due to its interactions with water. ${ }^{8}$ In our previous publication ${ }^{4}$ concerning ethanol inhibition of bioprosthetic heart valve cusp calcification, we showed that $80.0 \%$ ethanol pretreatment extracts almost all phospholipids and cholesterol from glutaraldehydecrosslinked cusps and also causes a permanent alteration in collagen conformation as assessed by Attenuated Total Reflectance-Fourier Transform Infrared Spectroscopy (ATR-FTIR). Thus, part of the mechanism of prevention of calcification by ethanol pretreatment may be explained by these results. The purpose of the present study was to assess the additional biomaterial effects on porcine bioprosthetic cusps brought about by the ethanol pretreatment and the relationship of such effects to the mechanism of prevention of calcification resulting from ethanol preincubation.

The specific objectives were to: (1) investigate the effects of ethanol on cuspal material stability in terms of residual glutaraldehyde content and collagenase degradation; (2) assess the effect of ethanol pretreatment on water-cusp tissue relationships using proton NMR and measurement of cuspal water content; and (3) study the cusp protein conformational changes due to ethanol pretreatment and the resulting effects on lipid-protein interactions.

\section{MATERIALS AND METHODS}

\section{Materials}

Absolute (200 proof) ethanol was obtained from McCormick Distilling Company Inc., Weston, MO. N-2hydroxyethylpiperazine- $\mathrm{N}^{\prime}-2-2$ ethanesulphonic acid (HEPES), tris(hydroxymethyl)amino methane (Tris), collagenase (from clostridium histolyticum) Type IA, and albumin bovine fraction $\mathrm{V}$ (BSA) and bovine serum with or without lipoprotein were obtained from Sigma (St. Louis, MO). Glutaraldehyde as an $8.0 \%$ EM grade solution was obtained from Polysciences (Warrington, PA). Calcium chloride $\left(\mathrm{CaCl}_{2}\right)$ was obtained from J.T. Baker, Inc. (Phillisburg, NJ). Radioactive glutaraldehyde $\left(1,5-{ }^{3} \mathrm{H}\right.$ glutaraldehyde, custom synthesis, $98.5 \mu \mathrm{ci} / \mu \mathrm{L})$, radioactive cholesterol $\left(4-{ }^{14} \mathrm{C}\right.$ labeled, $56.1 \mathrm{mCi} / \mathrm{mmol}$ ), and "Solvable" (a tissue and gel solubilizer) were obtained from DuPont (NEN ${ }^{\circledR}$ Research Products, Boston, MA). Ketamine hydrochloride (Aveco,
Fort Dodge, IA), and Rompun ${ }^{\circledR}$ (Haver, Shawnee, KS) were used for rat anesthesia.

\section{Bioprosthetic tissue preparation}

\section{Glutaraldehyde fixation protocols}

Fresh porcine aortic heart valves were shipped on ice from St. Jude Medical, Inc. (Minneapolis, MN) to the laboratory within $24 \mathrm{~h}$ of slaughter. Cusps were separated and rinsed several times with sterile saline. The cusp samples were crosslinked in a $0.6 \%$ glutaraldehyde solution (diluted from $8.0 \%$ aqueous solution) buffered with $50 \mathrm{mM}$ of HEPES at $\mathrm{pH} 7.4$, then transferred after $24 \mathrm{~h}$ to $0.2 \%$ glutaraldehyde solution in the same buffer for storage at room temperature for at least 1 week to achieve complete fixation.

Ethanol exposure conditions following glutaraldehyde crosslinking (for in vitro and rat subdermal studies)

Glutaraldehyde crosslinked porcine aortic valve cusps were placed in aqueous ethanol solutions $(10 \mathrm{~mL} / \mathrm{valve}$ cusps) with concentrations of 20.0, 40.0, 60.0, 80.0\% (v/v), and $100.0 \%$ (nonbuffered) prepared in HEPES buffer at $\mathrm{pH}$ 7.4. The solutions were kept on a shaker bath at room temperature $\left(25^{\circ} \mathrm{C}\right)$ for $24 \mathrm{~h}$, and then the cusps were stored in nonbuffered sterile saline $(0.9 \% \mathrm{NaCl})$ for $24 \mathrm{~h}$ to remove traces of ethanol prior to use for in vitro studies and rat subdermal implantation.

\section{Glutaraldehyde extraction by ethanol}

Fresh porcine aortic valve cusps (30) were fixed with radioactive glutaraldehyde $(18.4 \mu \mathrm{Ci} / \mathrm{mmol})$ with the same protocol discussed above for nonradioactive glutaraldehyde. After complete fixation, all samples were rinsed briefly with distilled water and then divided in three groups of ten samples each. The first group of samples (control) was rinsed with HEPES buffer for $24 \mathrm{~h}$; the second group of samples was treated with $40 \%$ ethanol in HEPES buffer for $24 \mathrm{~h}$, and the third group of samples was treated with $80 \%$ ethanol in HEPES buffer for $24 \mathrm{~h}$. After pretreatment the samples again were rinsed briefly with distilled water and then lyophilized. All samples were weighed and then digested in "Solvable" ( $1 \mathrm{~mL} /$ cusp) at $65^{\circ} \mathrm{C}$. After complete dissolution, $5 \mathrm{~mL}$ of scintillation cocktail was added to each vial and counted for glutaraldehyde radioactivity using a liquid scintillation counter (LC 3801, Beckman, Irvine, CA).

\section{Collagenase assay protocol}

Cusp samples (control and ethanol pretreated) were rinsed free of salts and chemicals using double distilled wa- 
ter and then lyophilized. Weighed samples of the dry cusps (10-15 mg) were placed in $1.2 \mathrm{~mL}$ of collagenase solution (2 $\mathrm{mg} / \mathrm{mL}$, in tris buffer, $0.05 \mathrm{M}$, pH 7.4 containing $0.36 \mathrm{mM}$ $\left.\mathrm{CaCl}_{2}\right)$ in Eppendorf tubes. The solutions were placed at $37^{\circ} \mathrm{C}$ on a shaker $(200 \mathrm{rpm})$ for $24 \mathrm{~h}$. The collagenase solution was removed and the remaining cusp samples were washed with water three times and then lyophilized. From the difference between final cusp weight remaining in the tube and initial weight, the fraction of undergraded cusp was obtained for each sample.

\section{Cusp tissue water content}

Glutaraldehyde-treated cusps (control and ethanol pretreated) were weighed in the wet state after blotting on a filter paper to remove surface water and lyophilized. The dry weight of the cusp samples was obtained after lyophilization, and the percent of water content in the cusps was calculated by the following formula: percent water content = $100 \times$ (wet weight-dry weight)/wet weight.

\section{Solid state proton NMR}

Four-five cusp samples from each group (control and ethanol pretreated) that had been equilibrated in distilled water were taken out and blotted on filter paper to remove any surface water. These cusps then were placed in an NMR tube (10 $\mathrm{mm}$ in diameter). The samples were analyzed with $\mathrm{NMR}$ at $40^{\circ} \mathrm{C}$. Solid state nuclear magnetic resonance spectrometer [Bruker Minispec, PC100, Bruker Spectrospin (Canada) Ltd., Milton, Ontario] was used to obtain spinlattice relaxation times (T1). ${ }^{9,10} \mathrm{~T} 1$ values were obtained from an inversion recovery pulse sequence (180-TD-90) in which the amplitude of the free induction decay (FID) was measured as a function of the interpulse distance TD. TD was varied from $1 \mathrm{~ms}$ to at least five times T1. The spectrometer was calibrated for each sample to assure accurate duration of $90^{\circ}$ and $180^{\circ}$ radiofrequency pulses.

\section{Calcium diffusion studies}

Diffusion cells (two chamber) were fabricated from Teflon ${ }^{\circledR}$ with each chamber volume of $1.5 \mathrm{~mL}$. A moist cusp sample was placed as diffusion barrier between the two chambers and checked carefully for any leaks. Then one chamber was filled with $1 \mathrm{~mL}$ of calcium chloride solution in HEPES (50 mM, pH 7.4) buffer $\left(0.2 \% \mathrm{CaCl}_{2}, 18 \mathrm{~mol} / \mathrm{L} \mathrm{Ca}\right)$, while $1 \mathrm{~mL}$ of HEPES buffer was added to the other side. The diffusion of calcium ions from one side to the other side through the cusp samples was monitored at $37^{\circ} \mathrm{C}$ by periodic sampling followed by calcium analyses using atomic absorption spectroscopy (AA). The buffer side was replenished with fresh buffer solution at each time point. Their diffusivities were calculated based on steady-state equilibrium, as described by Johnston et al, ${ }^{11}$ using the equation ${ }^{12}$

$$
\mathrm{D}=\mathrm{L}^{2} / 6\left(\mathrm{t}_{\mathrm{lag}}\right)
$$

where $\mathrm{D}$ is diffusivity, $\mathrm{L}$ is thickness of cusp, and $\mathrm{t}_{\text {lag }}$ is lag time.

\section{Cholesterol uptake studies}

Glutaraldehyde-crosslinked porcine aortic cusps were incubated in bovine serum with lipoprotein (BS + LP) containing $179 \mathrm{mg} / \mathrm{dL}$ of cholesterol and bovine serum without lipoprotein (BS-LP), each $100 \mathrm{~mL}$ sample spiked with $50 \mu \mathrm{L}$ of radioactive cholesterol $\left(4-^{14} \mathrm{C}, 0.040 \mathrm{mCi} / \mathrm{mL}\right)$ for $24 \mathrm{~h}$. All incubations were conducted at $37^{\circ} \mathrm{C}$ on a shaker at 100 $120 \mathrm{rpm}$. After the incubations, cusp samples were rinsed with distilled water and lyophilized. The dry-weighed samples then were digested in tissue solubilizer ("Solvable") and counted for radioactivity on a liquid scintillation counter.

\section{Rat implant protocols for cuspal FTIR analysis at explant}

Male weanling rats (50-60 g, CD, Sprague-Dawley, Charles River Laboratories, Burlington, MA) were anesthetized by an intramuscular injection of Ketamine and Rompun (4:3), 0.001 cc per gram body weight. Under general anesthesia, two subdermal pouches were created on the abdominal wall of each rat, as described previously, ${ }^{13}$ and two cuspal samples (either control or ethanol-pretreated cusps, washed with sterile saline to remove any traces of solvents and glutaraldehyde) were implanted in these pouches. The rats (5 per group) were sacrificed by $\mathrm{CO}_{2}$ asphyxiation after 7 days. The cusp samples were explanted and rinsed with saline solution for ATR-FTIR analysis and calcium assay.

\section{Infrared spectroscopy (ATR-FTIR)}

Hydrated, glutaraldehyde-crosslinked porcine aortic valve cusps (either control or ethanol pretreated) were used for FTIR studies. A Perkin-Elmer (Model 1740) FTIR spectrometer was equipped with a horizontal attenuated total reflectance ZnSe cell (ATR, SpectraTech Inc., Stamford, CT). A water spectrum was obtained as a reference and then subtracted from the sample by the instrument-controlled computer. The cusps were equilibrated in double-distilled water and blotted on a filter paper. The hydrated samples then were placed on an ATR cell and pressed with a sponge to obtain good surface contact between the cell and the sample. Fifty scans were obtained with a resolution of 4 $\mathrm{cm}^{-1}$. The spectra then were deconvoluted in the region of 1800-1000 $\mathrm{cm}^{-1}$ with the supplied software program (IR Data Manager, Perkin-Elmer) to resolve the different amide bands. 


\section{Statistical analysis}

Data were calculated as means \pm standard error of the mean. Differences between experimental groups were tested for significance using Student's $t$ test. Correlation coefficients and regression constants were calculated in appropriate studies. Results were termed significant when $p<0.05$.

\section{RESULTS}

The present results demonstrate that ethanol pretreatment of the porcine cusp tissue do not affect material stability but do have significant effects on collagen conformation and cuspal-water and cuspal-lipid interactions, which may in part explain the mechanism of inhibition of calcification by ethanol pretreatment.

\section{ATR-FTIR results}

An overlay FTIR spectra of control unimplanted cusps and control cusps after 7 days of subdermal implantation in rats is shown in Figure 1(a). An array of emerging peaks in the control cusps were seen in the amide I region of the spectra $(1700-1600 \mathrm{~cm}-1$ region) due to implantation, suggesting conformational changes in collagen and/or adsorption of additional proteins. An overlay FTIR spectra of ethanol pretreated unimplanted cusp samples and ethanol pretreated cusp samples after 7 days of subdermal implantation in rats is shown in Figure 1(b). The explanted cusps pretreated with $80.0 \%$ ethanol for $24 \mathrm{~h}$ demonstrated a collagen conformation that was much more stabilized (no new peaks appearing in the amide I region after implantation as compared to unimplanted samples) [Fig. 1(b)]. Thus, the conformational changes brought about by ethanol pretreatment were persistent even after 7 days of rat subdermal implantation.

\section{Proton NMR results}

The T1 values of the cusps were related to the ethanol concentration used for pretreatment and water content of the cuspal tissue. A correlation was observed between the T1 values and percent of ethanol pretreatment [Fig. 2(a)] with a trend showing that the higher proportions of ethanol in the pretreatment solution resulted in lower T1 values. This also was associated with a decrease in the total water content in the cusp with ethanol pretreatments. When the per-

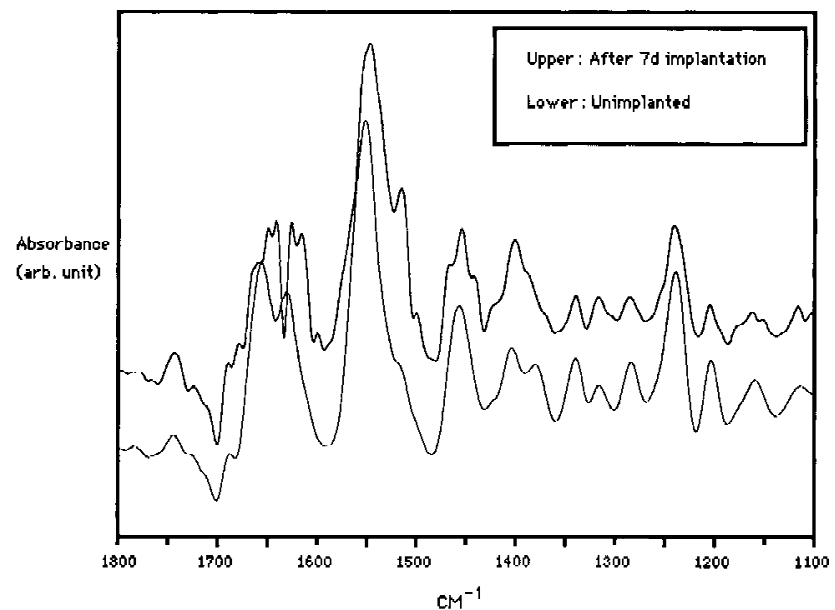

(a)

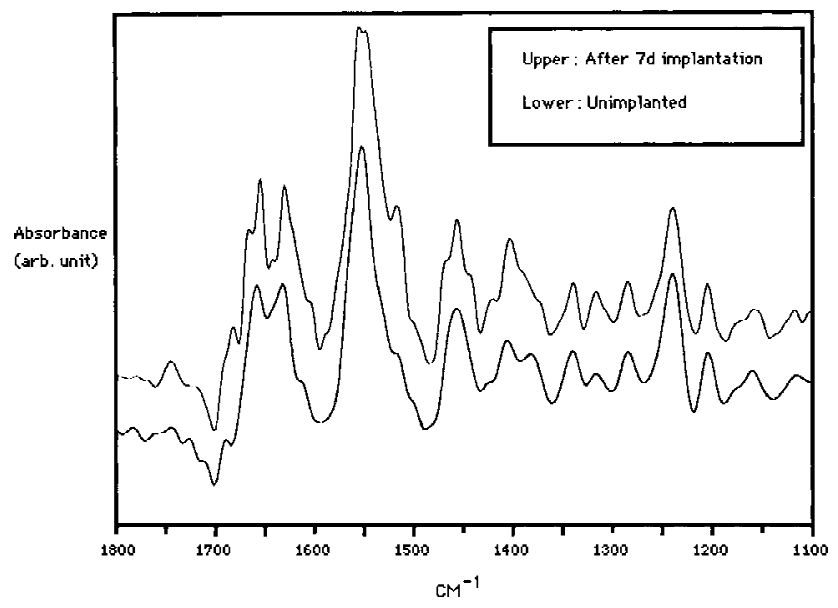

(b)

Figure 1. (a) Overlay of ATR-FTIR spectra of glutaraldehyde-crosslinked control unimplanted cusps and control cusp implanted subdermally in rats for 7 days. Note the changes in the Amide I region of spectra after the implantation. (b) Overlay of ATR-FTIR spectra of glutaraldehydecrosslinked cusps: $80 \%$ ethanol-pretreated (unimplanted) and $80 \%$ ethanol-pretreated cusps implanted subdermally in rats for 7 days.

cent of water content in the cusp was measured, a correlation $(r=0.924)$ was observed between relaxation time (T1) and the percent of water content in the cusps [Fig. 2(b)].

\section{Calcium diffusion studies}

No statistical differences in calcium diffusion across the cusps were observed between the control cusps and $80.0 \%$ ethanol pretreated cusps (Fig. 3). The cumulative amounts of free calcium diffused across the samples after $60 \mathrm{~min}$ were $198.9 \pm 11.3 \mu \mathrm{g}$ and 187.81 $\pm 17.9 \mu \mathrm{g}$ with average diffusivity of $1.62 \pm 0.13 \times 10^{-3}$ $\mathrm{cm}^{2} / \mathrm{h}$ and $1.79 \pm 0.38 \times 10^{-3} \mathrm{~cm}^{2} / \mathrm{h}$ (average $\pm \mathrm{SEM}$ ) for control and ethanol pretreated cusps, respectively. 


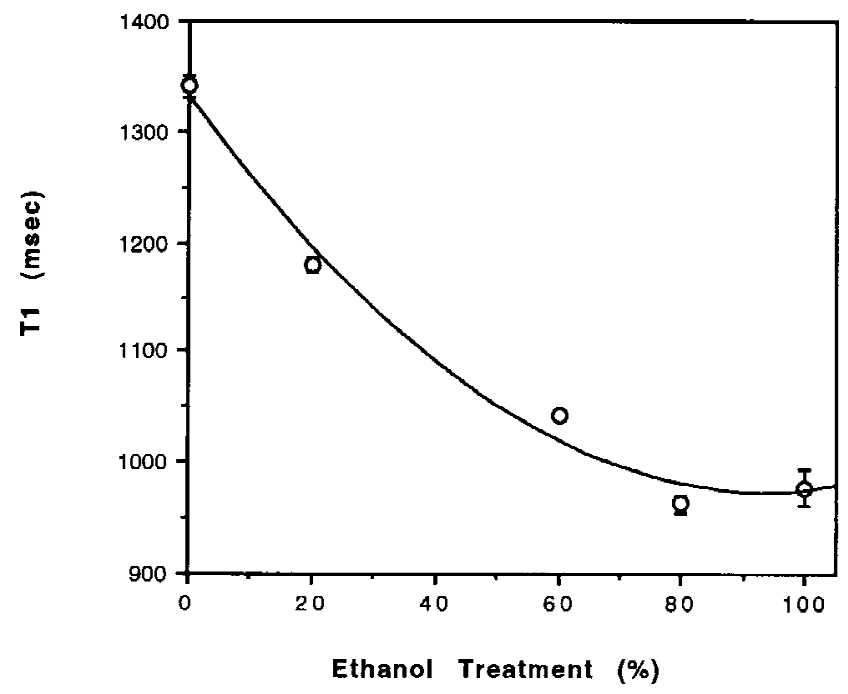

(a)

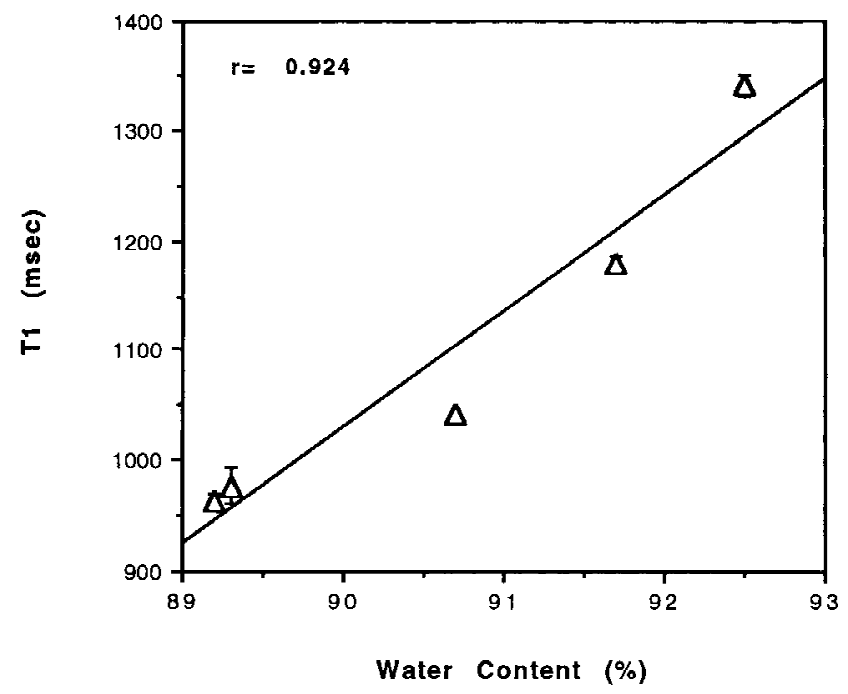

(b)

Figure 2. (a) Correlation of spin-lattice relaxation times (T1) as obtained by solid state NMR spectroscopy for glutaraldehyde-fixed cusp samples pretreated with various concentrations of ethanol for $24 \mathrm{~h}$; (b) shows T1 for cusp samples linearly correlates with the water content data.

\section{Cholesterol uptake studies}

When glutaraldehyde-crosslinked porcine aortic cusp samples were incubated with bovine serum with lipoprotein $(B S+L P)$, significant amounts of cholesterol were adsorbed on the cuspal samples as compared to incubations in bovine serum without lipoprotein (BS - LP, Table I). Cusp samples treated with $40.0 \%$ ethanol incubated with bovine serum showed no change in cholesterol uptake as compared to control samples. However, when cusp samples were treated with $80.0 \%$ ethanol for $24 \mathrm{~h}$, a significant reduction in cholesterol uptake was seen at the $24 \mathrm{~h}$ incubation period (Table I).

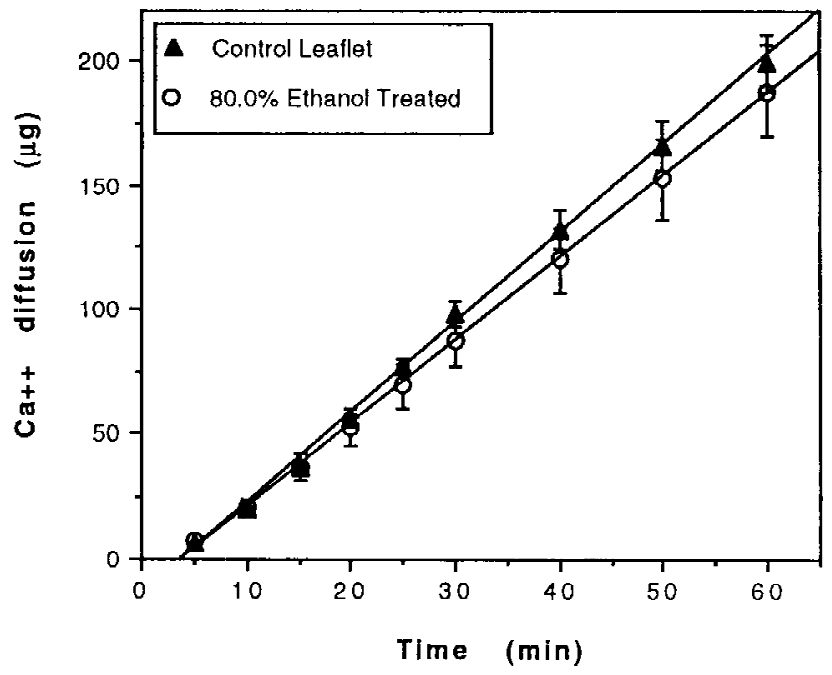

Figure 3. Diffusion of calcium across glutaraldehyde-fixed cusp samples. The concentration of calcium chloride solution is $0.2 \%$. Each data point represents the average of three replicates \pm SEM.

\section{Glutaraldehyde content of cusps after ethanol pretreatment}

The results demonstrated that the amount of radioactive glutaraldehyde remaining in the cusp samples after $40.0 \%$ and $80.0 \%$ ethanol pretreatment for $24 \mathrm{~h}$ was not substantially changed compared to control samples (Table II).

\section{Collagenase assay}

A collagenase assay was used as a means to assess material stability after the pretreatments. Results are depicted in Table III. As expected, uncrosslinked fresh porcine aortic cusps were almost completely digested by collagenase. However, when the cusps were crosslinked with glutaraldehyde, they significantly resisted digestion by collagenase enzyme. After various ethanol pretreatments for $24 \mathrm{~h}$, higher resistance to the

TABLE I

Cholesterol Uptake Studies

\begin{tabular}{lcc}
\hline & $\begin{array}{c}\text { Radioactive } \\
\text { Cholesterol Uptake } \\
(\mu \mathrm{g} / \mathrm{mg} \text { dry tissue }) \\
\pm \text { SE in }\end{array}$ & $\begin{array}{c}\text { Radioactive } \\
\text { Cholesterol Uptake } \\
(\mu \mathrm{g} / \mathrm{mg} \text { dry tissue) } \\
\pm \text { SE in }\end{array}$ \\
Pretreatment & $\begin{array}{c}\text { Medium (BS-LP) } \\
\text { Medium }(\mathrm{BS}+\mathrm{LP})\end{array}$ \\
\hline Control & $0.11 \pm 0.006$ & $20.31 \pm 1.20$ \\
$40 \%$ Ethanol & $0.13 \pm 0.02$ & $18.83 \pm 0.75$ \\
$80 \%$ Ethanol & $0.029 \pm 0.002^{*}$ & $5.15 \pm 0.34^{*}$
\end{tabular}

$n=5$ per group, BS-LP represents bovine serum without lipo-protein, and BS + LP represents bovine serum with lipoprotein. Incubations were carried out for $24 \mathrm{~h}$ at $37^{\circ} \mathrm{C}$. ${ }^{*} \mathrm{P}<$ 0.005 vs. control. 
TABLE II

Radioactive Glutaraldehyde Uptake Studies

\begin{tabular}{lc}
\hline \multicolumn{1}{c}{ Treatment } & $\begin{array}{c}\text { Amount of Glutaraldehyde } \\
\text { in Cusps } \\
(\mu \mathrm{g} / \mathrm{mg} \text { dry tissue }) \pm S E\end{array}$ \\
\hline Control & $11.7 \pm 0.08$ \\
$40 \%$ Ethanol for $24 \mathrm{~h}$ & $11.6 \pm 0.08$ \\
$80 \%$ Ethanol for $24 \mathrm{~h}$ & $12.8 \pm 0.06$ \\
\hline
\end{tabular}

$n=10$ per group.

collagenase digestion was seen as compared to glutaraldehyde crosslinked cusps $(p<0.002)$ for $40 \%$ or more ethanol-pretreated cusps.

\section{DISCUSSION}

The mechanism of how ethanol pretreatment inhibits bioprosthetic cusp calcification has been further elucidated with our results that demonstrated that the conformational change in collagen structure within cusps brought about by ethanol was persistent even after 7 days of implantation in rats and that ethanol preincubation significantly affects cuspal interactions with water and lipids and enhances cuspal resistance to collagenase.

\section{ATR-FTIR studies}

Infrared spectroscopy has been used in the past for collagen investigations to understand the conformational changes due to denaturation. ${ }^{14-17}$ In particular, the amide I region of the spectra (amide carbonyl stretching, $1690-1625 \mathrm{~cm}^{-1}$ ) is very sensitive to subtle changes in the triple helical structure of the collagen. ${ }^{15}$

TABLE III Collagenase Digestion Studies

\begin{tabular}{|c|c|}
\hline Group & $\begin{array}{c}\text { Residual Tissue Weight } \\
\text { After Collagenase } \\
\text { Digestion }(\%) \pm \text { S.E. }\end{array}$ \\
\hline Fresh uncrosslinked cusps & $4.1 \pm 0.21$ \\
\hline Glutaraldehyde-crosslinked cusps & $75.3 \pm 1.09$ \\
\hline $\begin{array}{l}\text { Glutaraldehyde-crosslinked cusps } \\
\text { pretreated with } 20 \% \text { ethanol }\end{array}$ & $72.0 \pm 3.99$ \\
\hline $\begin{array}{l}\text { Glutaraldehyde-crosslinked cusps } \\
\text { pretreated with } 40 \% \text { ethanol }\end{array}$ & $85.8 \pm 2.13^{*}$ \\
\hline $\begin{array}{l}\text { Glutaraldehyde-crosslinked cusps } \\
\text { pretreated with } 60 \% \text { ethanol }\end{array}$ & $87.3 \pm 0.64^{*}$ \\
\hline $\begin{array}{l}\text { Glutaraldehyde-crosslinked cusps } \\
\text { pretreated with } 80 \% \text { ethanol }\end{array}$ & $86.5 \pm 1.04^{*}$ \\
\hline $\begin{array}{l}\text { Glutaraldehyde-crosslinked cusps } \\
\text { pretreated with } 100 \% \text { ethanol }\end{array}$ & $84.3 \pm 2.21^{*}$ \\
\hline
\end{tabular}

This region can be resolved into various components due to nonequivalent amide carbonyls present in the triple helix. The $1660 \mathrm{~cm}^{-1}$ band was assigned to prolyl carbonyls directed inside the triple helix (capable of intramolecular hydrogen bonding) while a band at $1630 \mathrm{~cm}^{-1}$ was assigned to amide carbonyls directed outwards in the triple helix and are capable of intermolecular hydrogen bonds with water molecules. A downward shift in the amide I region is indicative of denaturation or a "coil" opening of the collagen molecule. ${ }^{15}$

In our previous publication, ${ }^{4}$ we showed that the $80 \%$ ethanol pretreatment of the porcine valve cusp tissue resulted in changes in the collagen conformation, as assessed by changes in the amide I region of the FTIR spectra. The resulting change was irreversible even after the cusp tissue was re-equilibrated in water for prolonged periods of time. In the present study, we extended these observations to determine if such a change in the collagen conformation was persistent after subdermal implantation in rats for 7 days (by this time calcification progresses significantly in this model). FTIR spectra of control cusp samples after 7 days of implantation showed significant changes in the amide I region, with a trend of downward shifting of all the peaks and the appearance of new peaks as compared to unimplanted control samples [Fig. 1(a)]. Also, the peak height ratio of $1660 / 1630 \mathrm{~cm}^{-1}$ changed significantly, suggesting severe degeneration of the collagen triple helical structure. On the other hand, the cusp samples pretreated with $80 \%$ ethanol for $24 \mathrm{~h}$ did not show dramatic shifts in either position or peak height ratio in the amide I region of the FTIR spectra after the subdermal implantation in rats for 7 days [Fig. 1(b)]. These data strongly suggest that the changes brought about by ethanol pretreatment in collagen conformation are stable and may be important in explaining the anticalcification mechanism. Such a conformational change may be responsible for the observed reduced cuspal adsorption of lipids or proteins due to ethanol pretreatment. This study also warrants further research on protein-protein and protein-lipid interactions with respect to collagen and their roles in bioprosthetic heart valve calcification.

\section{Ethanol effects on cusp tissue interactions with water and calcium}

Proton NMR spin-lattice relaxation times (T1) have been used in the past for water structure and moisture content analyses, ${ }^{18}$ and have been applied to biomaterials to assess tissue-water interactions. ${ }^{9,10,19-21}$ In our studies, the equilibrium water content for the cusps show small but consistent lowering with ethanol pretreatments [Fig. 2(a)]. The proton NMR relax- 
ation time (T1) also resulted in a marked decrease in this parameter, correlating with the concentration of the ethanol pretreatment solution [Fig. 2(b)]. The data suggest that collagen, the major protein present in cuspal tissue, is interacting differently with water after the ethanol pretreatments.

The decrease in the water content of the cusps, however, did not change cusp tissue-calcium interactions. When calcium ion diffusion across the cusp tissues was studied for control and ethanol-pretreated cusp samples, no statistically significant change in bulk calcium ion flux due to ethanol pretreatment was observed (Fig. 3). It has been reported in the past for other anticalcification treatments of amino oleic acid (AOA) that AOA pretreatment greatly reduces the calcium ion flux. ${ }^{22}$ Part of the mechanism of AOA anticalcification was ascribed to this effect. Thus, the mechanism of anticalcification of ethanol pretreatment may not be due to its effect on changes in calciumcuspal tissue interactions.

\section{Ethanol effects on cusp tissue interactions with cholesterol}

The $80.0 \%$ ethanol pretreatment of glutaraldehydecrosslinked cusps extracted almost all cholesterol and phospholipids from the cusp samples. ${ }^{4}$ It has been hypothesized that phospholipids present in devitalized cells of bioprostheses are an initial source of phosphorus in heart valve calcification due to phosphoester hydrolysis. ${ }^{23}$ Other studies also have looked at the connection between cholesterol and calcification in atherosclerotic plaques. ${ }^{24-26}$ It has been shown that cholesterol levels increase progressively with age, correlating directly with the risk of coronary artery disease. ${ }^{27}$ Cholesterol also alters calcium transit across cell membranes, cystolic calcium levels, and membrane fluidity in arterial smooth muscle cells. ${ }^{28}$ The mechanism by which cholesterol content of the cell membrane correlates with intracellular calcification remains incompletely understood. The role of cholesterol in pathologic calcification of bioprosthetic heart valves (either inherent or absorbed during implantation) has not been studied to a significant extent. In the present study, we examined the cholesterol uptake of the cusp samples after the ethanol pretreatment (Table I). Control cusp samples when incubated in bovine serum with lipoprotein adsorbed significant amount of cholesterol. When cusp samples were treated with $40.0 \%$ ethanol (at this concentration the pretreatment is not effective for calcification prevention ${ }^{4}$ ), no change was seen in the amount of cholesterol uptake. However, at $80.0 \%$ ethanol pretreatment (which was found to be highly efficacious in preventing calcification), a four fold reduction in cholesterol uptake was observed. The data indicate that ethanol pretreatment results in a significant material change unfavorable for the adsorption of lipids.

\section{Material stability considerations}

Ideal anticalcification treatments for a bioprosthetic heart valve should not impede normal valve function and durability. ${ }^{29}$ We demonstrated in an earlier communication that ethanol treatment did not change the thermal denaturation temperature $\left(T_{D}\right)$ of the crosslinked cusps. ${ }^{4} \mathrm{~T}_{\mathrm{D}}$ has been used in the past as a measure of the extent of crosslinking. ${ }^{30-34}$ In this work, we have performed additional studies to understand the changes in the extent of glutaraldehyde crosslinking due to ethanol pretreatment. When cusp samples were crosslinked with radioactive glutaraldehyde. $\left({ }^{14} \mathrm{C}\right.$-labeled) and then treated with $80.0 \%$ ethanol for $24 \mathrm{~h}$, the amount of glutaraldehyde in the cusps was not altered after the ethanol pretreatment (Table II), suggesting that ethanol pretreatment did not facilitate reversing the Schiff's base reaction of glutaraldehyde with cuspal tissue and that no loosely bound glutaraldehyde leached out during the ethanol pretreatment.

Clostridial collagenase degrades native Type I collagen under in vitro conditions. It has been shown previously that glutaraldehyde fixation confers significant resistance to degradation by collagenase..$^{35}$ Thus, enzyme degradation studies have been used as an indicator for determining the extent of crosslinking. ${ }^{32,36}$ Fresh uncrosslinked porcine cusps when subjected to collagenase degradation underwent almost complete dissolution while crosslinking with glutaraldehyde significantly stabilized the collagen (Table III). However, after $40 \%$ or higher ethanol pretreatments, resistance to collagenase digestion was increased, suggesting that at higher concentrations of ethanol pretreatment, tissue structure is much more stabilized. This may be due to permanent structural changes in collagen, as observed by FTIR spectroscopy, ${ }^{4}$ and altered water interactions.

These observations are important in the sense that glutaraldehyde fixation is an essential part of bioprosthetic heart valve preparative procedures as it prevents material degradation and also makes tissue less immunogenic. Also, previously used anticalcification treatments, such as polyoxyethylene ether (Triton X100 ) and N-lauryl sarcosine treatments, have been found to alter the material stability that resulted in cuspal perforations after 20 weeks of implantation in the mitral position in sheep. ${ }^{37}$ The data obtained in this study (radioactive glutaraldehyde studies and collagenase assay) and previous thermal denaturation temperature $\left(\mathrm{T}_{\mathrm{D}}\right)$ studies ${ }^{4}$ strongly suggest that etha- 
nol pretreatment does not diminish the stability of glutaraldehyde-crosslinked porcine cusp samples.

\section{CONCLUSIONS}

The present studies extend our understanding of the mechanism of ethanol inhibition of bioprosthetic heart valve calcification. In particular, we show that (1) the collagen conformational change (per FTIR results) brought about by ethanol pretreatment was stable even after subdermal implantation of the samples for 7 days; (2) ethanol pretreatment permanently decreased the amount of water in the cusp samples as evaluated by the water content and by solid state proton NMR (spin-lattice relaxation time, T1 of water molecules within the cusp samples); (3) ethanol pretreatment enhanced the material stability as assessed by increased resistance to collagenase digestion; (4) cuspal ethanol pretreatment did not affect cuspal glutaraldehyde content, thus the ethanol effects cannot be solely explained due to glutaraldehyde extraction; (5) the material changes brought about by ethanol pretreatment also significantly altered the interactions of cusp tissue with proteins and lipids. In particular, in vitro cholesterol uptake was greatly reduced due to $80 \%$ ethanol pretreatment. Therefore, the anticalcification effects of the ethanol pretreatment may be due to its multi-component effects on cusp tissue material.

The authors thank Ardith Bates and Carmella Gantt for their secretarial assistance.

\section{References}

1. F. Schoen, J. Collins, and L. Cohn, "Long-term failure rate and morphologic correlations in porcine bioprosthetic heart valves," Am. J. Cardiol., 51, 957-964 (1983).

2. B. Potkin, C. McIntosh, R. Cannon, and W. Roberts, "Bioprostheses in tricuspid and mitral valve positions for 95 months with heavier calcific deposits on the right-sided valve," Am. J. Cardiol., 61, 947-949 (1988).

3. L. Pelletier, M. Carrier, Y. Leclerc, G. Lepage, P. deGuise, and I. Dyrda, "Porcine versus pericardial bioprostheses: A comparison of late results in 1,593 patients," Ann. Thorac. Surg., 47, 352-361 (1989).

4. N. R. Vyavahare, D. Hirsch, E. Lerner, J. Z. Baskin, F. J. Schoen, R. Bianco, H. S. Kruth, R. Zand, and R. J. Levy, "Prevention of bioprosthetic heart valve calcification by ethanol preincubation: Efficacy and mechanism," Circulation, 95, 479-488 (1997).

5. W. K. Ramp and D. N. Demaree, "Inhibition of net calcium efflux from bone by ethanol in vitro," Am. J. Physiol., 246, C30C36 (1984).

6. K. E. Friday and G. A. Howard, "Ethanol inhibits human bone cell proliferation and function in vitro," Metabolism, 40, 562-565 (1991).

7. E. Rubin and R. Hagai, "Ethanol-induced injury and adaptation in biological membranes," Fed. Proc., 41, 2465-2471 (1982).

8. M. S. Tung and T. J. O'Farrell, "The effect of ethanol on the solubility of dicalcium phosphate dihydrate in the system $\mathrm{Ca}(\mathrm{OH})_{2}-\mathrm{H}_{3} \mathrm{PO}_{4}-\mathrm{H}_{2} \mathrm{O}$ at $37^{\circ} \mathrm{C}$," J. Mol. Liq., 56, 237-243 (1993).

9. R. Kamman, K. Go, G. Stomp, C. Hulstaert, and H. Berendsen, "Changes in relaxation times T1 and T2 in rat tissues after biopsy and fixation," Magn. Reson. Imag., 3, 245-250 (1985).

10. T. Scholz, S. Fleagle, and D. Skorton, "In vitro NMR characterization of mammalian myocardium: Effect of specimen integrity on relaxation times," Magn. Reson. Med., 11, 367-370 (1989).

11. T. P. Johnston, J. A. Boyd, B. L. Ciesliga, F. J. Schoen, G. Amidon, and R. J. Levy, "Controlled release of ethanehydroxy diphosphonate from polyurethane reservoirs to inhibit calcification of bovine pericardium used in bioprosthetic heart valves," Int. J. Pharmaceut., 59, 95-104 (1990).

12. R. Baker, Diffusion Controlled Systems, R. Baker (ed.), Wiley, New York, 1987, pp. 39-83.

13. F. J. Schoen, J. Tsao, and R. J. Levy, "Calcification of bovine pericardium used in cardiac valve bioprostheses: Role of glutaraldehyde-modified structural components in bioprosthetic tissue mineralization," Am. J. Pathol., 123, 134-145 (1986).

14. B. Doyle, E. Bendit, and E. Blout, "Infrared spectroscopy of collagen and collagen-like peptides," Biopolymers, 14, 937-957 (1975).

15. A. George and A. Veis, "FTIRs in $\mathrm{H}_{2} \mathrm{O}$ demonstrate that collagen monomers undergo a conformational transition prior to thermal self-assembly in vitro," Biochem., 30, 2372-2377 (1991).

16. V. Renugopalkrishnan, G. Chandrakasan, S. Moore, T. Hutson, C. Berney, and R. Bhatnagar, "Bound water in collagen. Evidence from fourier transform infrared and fourier transform infrared photoacoustic spectroscopic study," Macromolecules, 22, 4121-4124 (1989).

17. H. Susi, J. Ard, and R. Carroll, "The infrared spectrum and water binding of collagen as a function of relative humidity," Biopolymers, 10, 1597-1604 (1971).

18. S. Yoshioka, Y. Aso, T. Otsuka, and S. Kojima, "Water mobility in poly(ethylene glycol)-, poly(vinylpyrrolidone)-, and gelatinwater systems, as indicated by dielectric relaxation time, spinlattice relaxation time, and water activity," J. Pharmaceut. Sci., 84, 1072-1077 (1995).

19. P. Bottomley, T. Foster, R. Argersinger, and L. Pfeifer, "A review of normal tissue hydrogen NMR relaxation times and relaxation mechanisms from 1-100 MHz: Dependence on tissue type, NMR frequency, temperature, species, excision and age," Med. Phys., 11, 425 (1984).

20. S. F. Akber, "Role of paramagnetic ions and water proton spin-lattice relaxation time in biological systems," Nuklearmedizin, 32, 52-56 (1993).

21. S. F. Akber, "A new perspective to assess relaxation time of tumor," Med. Hypotheses, 37, 24-26 (1992).

22. W. Chen, F. J. Schoen, and R. J. Levy, "Mechanism of efficacy of 2-amino oleic acid for inhibition of calcification of glutaraldehyde-pretreated porcine bioprosthetic heart valves," Circulation, 90, 323-329 (1994).

23. F. J. Schoen and R. J. Levy, "Heart valve bioprostheses: Antimineralization," Eur. J. Card. Thorac. Surg., 6 (Suppl. 1), S91S94 (1992).

24. A. Tanimura, D. H. McGregor, and H. C. Anderson, "Calcification in atherosclerosis. II. Animal studies," J. Exp. Pathol., 2, 275-297 (1986).

25. E. Rokita, T. Cichocki, D. Heck, L. Jarczyk, and A. Strzalkowski, "Calcification of aortic wall in cholesterol-fed rabbits," Atherosclerosis, 87, 183-193 (1991).

26. L. Bartolini, S. Casini, and V. Mittica, "The calcification of aortic plaques during experimental cholesterol atherogenesis in the rabbit and the 'regression'," Boll. Soc. Ital. Biol. Sper., 53, 2294-2297 (1977).

27. S. Kasim, "Cholesterol changes with aging: Their nature and significance," Geriatrics, 42, 73-82 (1987). 
28. M. Gleason, M. Medow, and T. Tulenko, "Excess membrane cholesterol alters calcium movements, cytosolic calcium levels, and membrane fluidity in arterial smooth muscle cells," Circ. Res., 69, 216-227 (1991).

29. F. J. Schoen, R. J. Levy, S. L. Hilbert, and R. W. Bianco, "Antimineralization treatments for bioprosthetic heart valves: Assessment of efficacy and safety," J. Thorac. Cardiovasc. Surg., 104, 1285-1288 (1992).

30. A. Finch and D. A. Ledward, "Shrinkage of collagen fibers-A differential scanning calorimetric study," Biochim. Biophys. Acta, 278, 433-439 (1972).

31. P. E. McClain and E. R. Wiley, "Differential scanning calorimeter studies of the thermal transitions of collagenImplications on structure and stability," J. Biol. Chem., 247, 692697 (1972).

32. H. Petite, I. Rault, A. Huc, P. Menasche, and D. Herbage, "Use of acyl azide method for crosslinking collagen-rich tissues such as pericardium," J. Biomed. Mater. Res., 24, 179-187 (1990).
33. A. Simionescu, D. Simionescu, and R. Deac, "Lysine-enhanced glutaraldehyde crosslinking of collagenous biomaterials," $J$. Biomed. Mater. Res., 25, 1495-1505 (1991).

34. W. K. Loke and E. Khor, "Validation of the shrinkage temperature of animal tissue for bioprosthetic heart valve application by differential scanning calorimetry," Biomaterials, 16, 251-258 (1995).

35. G. Golomb, F. J. Schoen, M. S. Smith, J. Linden, M. Dixon, and R. J. Levy, "The role of glutaraldehyde-induced cross-links in calcification of bovine pericardium used in cardiac valve bioprostheses," Am. J. Pathol., 127, 122-130 (1987).

36. E. Imamura, O. Sawatani, H. Koyanagi, Y. Noishiki, and T. Miyata, "Epoxy compounds as a new cross-linking agent for porcine aortic leaflets: Subcutaneous implant studies in rats," $J$. Card. Surg., 4, 50-57 (1989).

37. M. Jones, E. E. Eidbo, S. L. Hilbert, V. J. Ferrans, and R. E. Clark, "Anticalcification treatments of bioprosthetic heart valves: In vivo studies in sheep," J. Card. Surg., 4, 69-73 (1989). 